\title{
Corrigendum
}

\section{Corrigendum to "Evaluating the Importance of the Carotid Chemoreceptors in Controlling Breathing during Exercise in Man"}

\author{
M. J. Parkes \\ School of Sport, Exercise \& Rehabilitation Sciences, University of Birmingham, Edgbaston, Birmingham B15 2TT, UK \\ Correspondence should be addressed to M. J. Parkes; m.j.parkes@bham.ac.uk
}

Received 18 June 2015; Accepted 25 June 2015

Copyright (C) 2015 M. J. Parkes. This is an open access article distributed under the Creative Commons Attribution License, which permits unrestricted use, distribution, and reproduction in any medium, provided the original work is properly cited.

In the paper titled "Evaluating the Importance of the Carotid Chemoreceptors in Controlling Breathing during Exercise in Man," please note that in Figure 4(a) the top scale should read as follows: Equivalent altitude $(\mathrm{k} f \mathrm{f})$ calculated by Dripps (and not $\mathrm{km})$. 


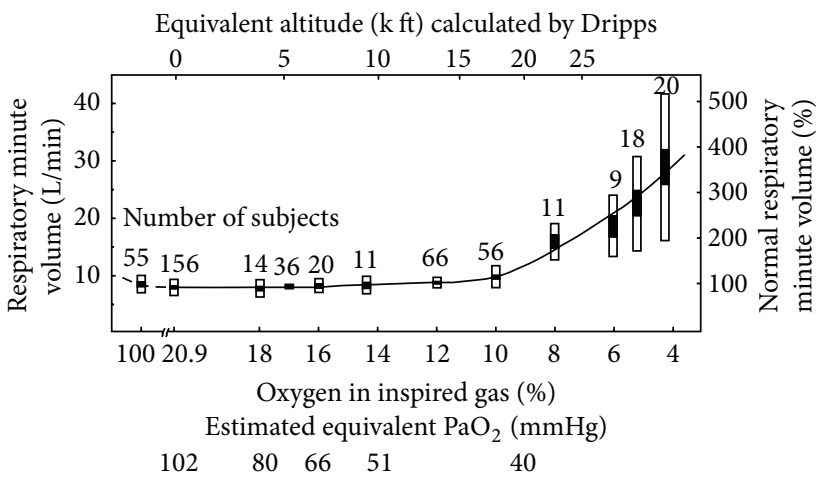

(a)

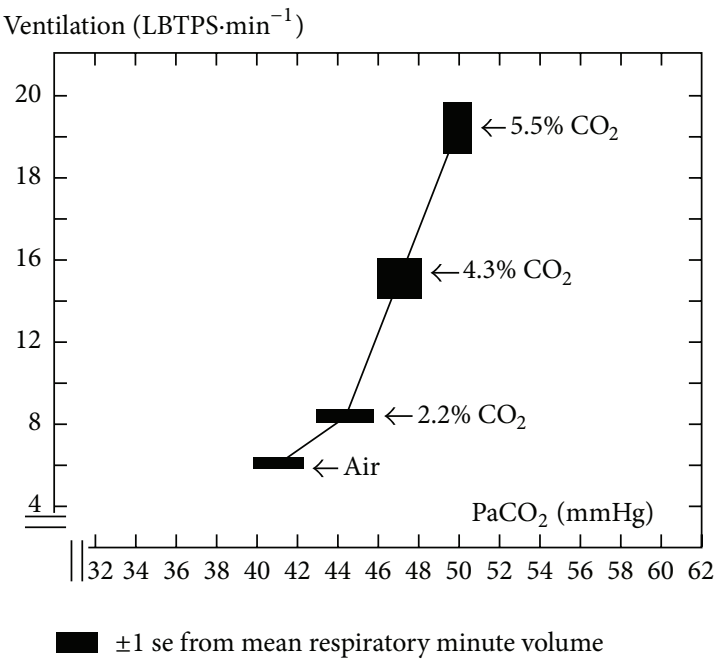

(b)

FIgURE 4: (a) Relative insensitivity of breathing at rest to artificially lowering $\mathrm{PO}_{2}$ in Man. Minute ventilation ( \pm se solid bars, \pm sd open bars) in normal subjects [87] as inspired oxygen is artificially lowered (strictly hypocapnic hypoxia exists once hyperventilation occurs). Equivalent $\mathrm{PaO}_{2}$ points are aligned on the $\mathrm{FiO}_{2}$ scale, with $\mathrm{PaO}_{2}$ estimated before hyperventilation occurs using the alveolar gas equation (assuming $760 \mathrm{mmHg}$ barometric pressure, $\mathrm{RQ}=0.8, \mathrm{PaO}_{2}=\mathrm{PAO}_{2}$, and $\mathrm{PaCO}_{2}=\mathrm{PACO}_{2}$ ), and the point afterwards is estimated based on dynamic forcing experiments in isocapnia (courtesy of Dr. G. A. Balanos). Reproduced with permission from Dripps et al., [87]. (b) Sensitivity of breathing at rest to artificially raising $\mathrm{PaCO}_{2}$ in Man. Minute ventilation and $\mathrm{PaCO}_{2}$ (femoral) in 8 healthy men [88] while inhaling 0-6\% $\mathrm{CO}_{2}$ in air at atmospheric pressure (mean slope is $2.5 \mathrm{~L} \cdot \mathrm{min}^{-1} \mathrm{mmHg}$ artificial $\mathrm{PaCO}_{2}$ rise). Reproduced with permission from Lambertsen et al. [88]. 

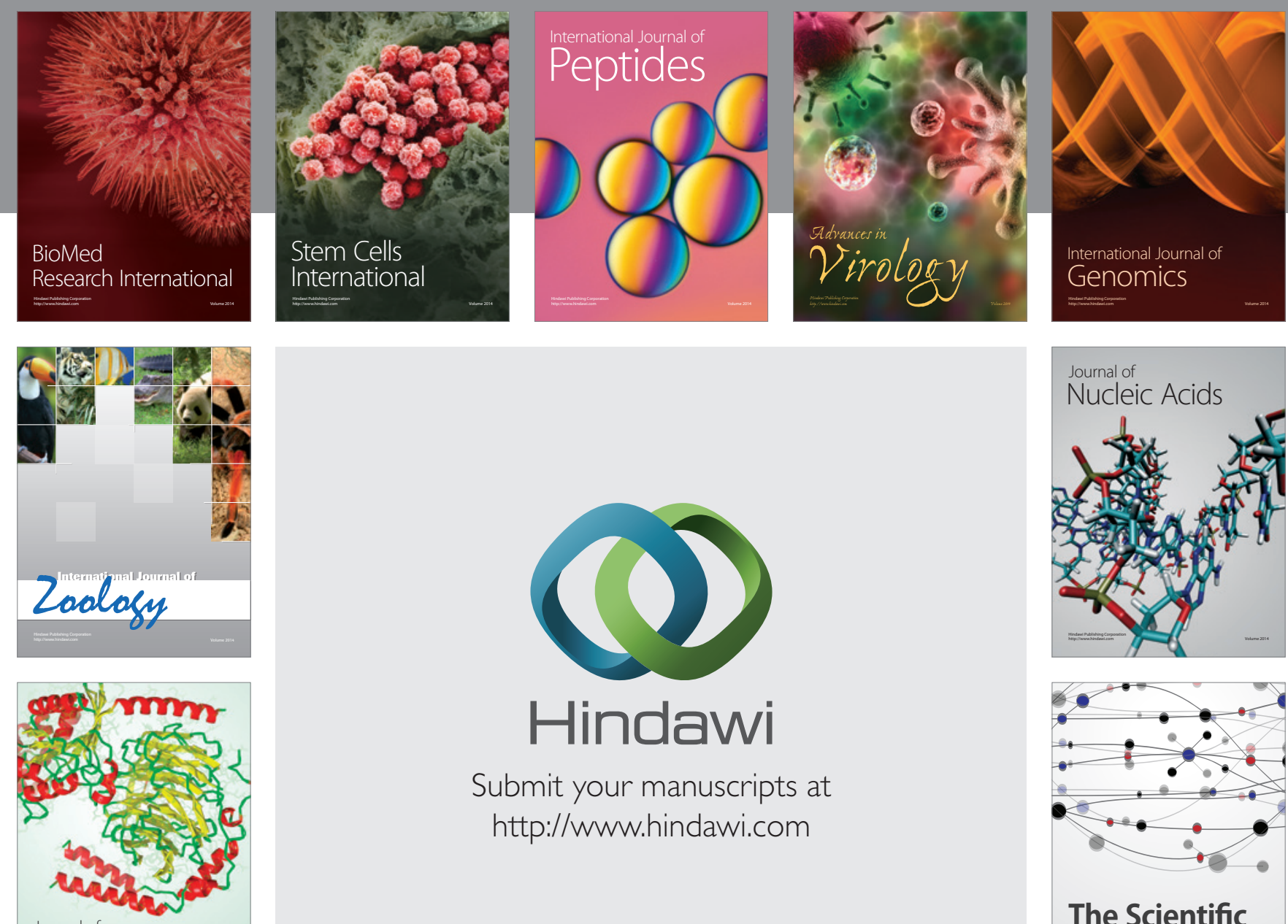

Submit your manuscripts at

http://www.hindawi.com

Journal of
Signal Transduction
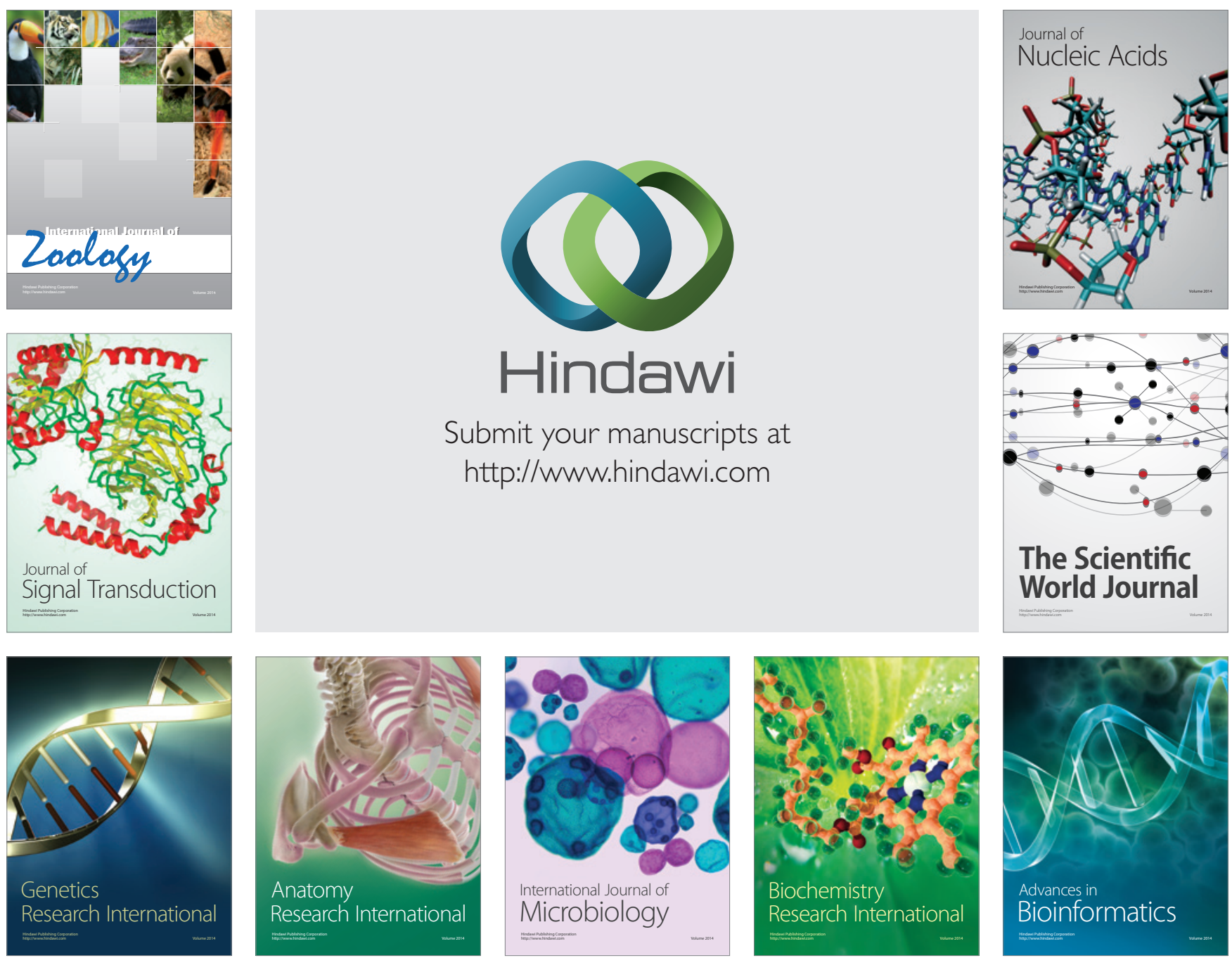

The Scientific World Journal
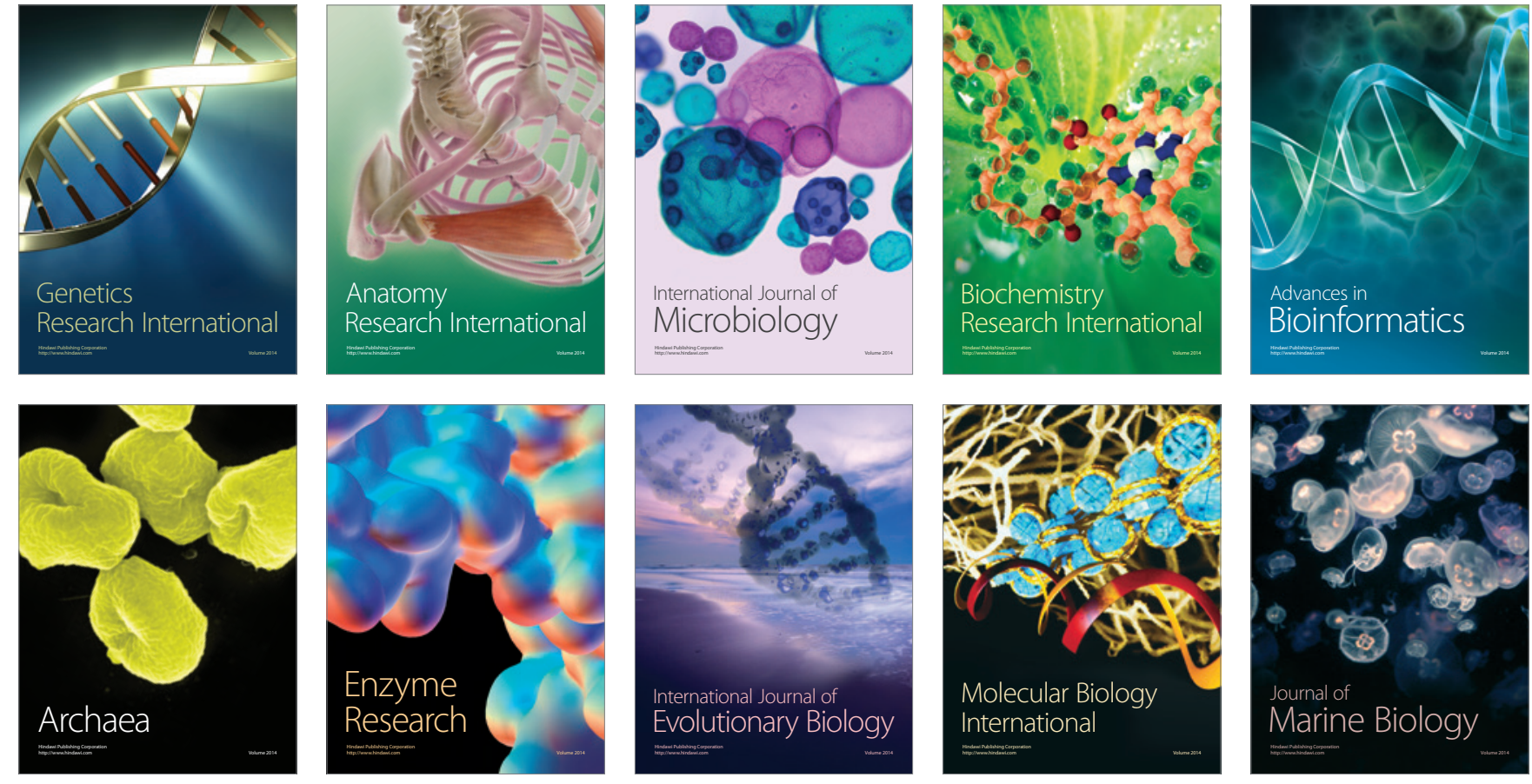